\title{
Factors Affecting Fertilizer Purchase Decision: Problem of Agricultural Marketing
}

\author{
Debdulal Dutta Roy' and Kaushik Choudhary²
}

\begin{abstract}
Fertilizer market is an important component of agricultural economy of the Asian countries. This study was carried out to explore factors affecting decision to purchase fertilizer by the farmers. Data were collected from 200 farmers through five-point Likert-type questionnaire constructed for current study. The questionnaire was used to seek farmers' opinion on the significance of the selected determinants to purchase fertilizer. These determinants are - price, fertilizer quality, brand, advertisement, soil quality, crop quality and landscapes. Results revealed that farmers gave more importance on quality of crops, fertilizer and landscape than price and advertising.
\end{abstract}

Key words: Agricultural marketing, Theory of planned behaviour

\section{INTRODUCTION AND OBJECTIVE}

In economic planning, agriculture has been often given the highest priority because economic growth depends on increased production of existing crops and diversified use of agricultural produce as industrial inputs. According to the World Bank, agriculture is the main source of food, income, and employment for the majority of population in developing countries.

In India, agriculture, with its allied sectors, is unquestionably the largest livelihood provider in the vast rural areas. It also contributes a significant figure to the Gross Domestic Product (GDP). Sustainable agriculture, in terms of food security, rural employment, and environmentally sustainable technologies such as soil conservation, sustainable natural resource management and biodiversity protection, are essential for holistic rural development. Indian agriculture and allied activities have witnessed a green revolution, a white revolution, a yellow revolution and a blue revolution. In this process, the role of agricultural marketing has remained vital.

1. Dr. Roy is Associate Professor at Indian Statistical Institute, Kolkata, India. Email: dduttaroy@gmail.com

2. Mr. Chaudhary, Associate Professor at Indian Institute of Technology and Management, Kolkata, India. 


\section{Agricultural Marketing}

Agriculture marketing involves a number of operations and processes through which raw materials and agricultural products move to the final consumers. Agricultural marketing is very important in agricultural production. In Nepal, where agriculture is regarded as the lifeblood for the development of the national economy, the movement of agricultural products from the terai to the hills and from the hills to the terai requires efficient and effective agricultural marketing network. Pokhrel and Thapa (2007) suggested group-marketing system as taking advantage of farmer's weak bargaining power and poor economic condition; marketing intermediaries were harassing and cheating them in different ways.

In India, agricultural marketing continues to be the mainstay of life for majority of the Indian population. It contributes around 25percent of the GDP and employs 65 percent of the workforce in the country. The Government of India under the ministry of agriculture has also set up specific commodity boards and export promotion council for monitoring and boosting the production, consumption, marketing and export of various agricultural commodities. There are three marketing functions involved in this, i.e., assembling, preparation for consumption and distribution. Indian agricultural market is mostly dominated by the fertilizer market.

\section{Fertilizer Purchase}

Fertilizer refers to any compound that contains one or more chemical elements, organic or inorganic, natural or synthetic, that is placed on or incorporated into the soil or applied to directly onto plants to achieve normal growth. The main supply sources of plant nutrients include organic manures, plant residues, biological nitrogen fixation and commercial inorganic fertilizers. Different chemical fertilizers contain substantial amount of one or more plant nutrients. The chemical fertilizers can be broadly classified into: nitrogen, phosphorus, and potassium fertilizers. A straight fertilizer contains only one of the nutrients. A compound fertilizer contains two or more nutrients. A complex fertilizer that is formed by mixing ingredients that react chemically, as opposed to a mechanical mixture of two or more fertilizers. Carbon, oxygen and hydrogen are directly supplied by air and water and therefore are not treated as nutrients by the fertilizer industry. In Nepal, farmers use both organic and inorganic fertilizers. Haefele, Bhattachan, Adhikari, Abon, Shresta (2014) observed that farmers applied less fertilizer in fertile fields and more inorganic in the non-fertile field.

There are 57 large fertilizer plants and 57 large-sized and 64 medium- and smallsized chemical fertilizer production units in India producing urea, DAP, Complex fertilizer, Ammonium Sulphate (AS) and Calcium Ammonium Nitrate (CAN). India ranks third in the world of fertilizer production. All categories of farmers (the small, medium and big farmers) purchase fertilizers. Decision to purchase the fertilizer requires adequate planning. This study aims at exploring the factors that farmers take into account in their purchase decisions. 


\section{Purchase Decisions}

The study of the determinants of consumer purchase decision has become an integral part of strategic marketing plan. Consumers are the most important part of any business. The knowledge of the determinants of consumer purchase decision helps the marketer to properly segment the market and attracts the target customers. Marketers determine their strategy in accordance with the needs and want of the consumers. Price, quality, brand, advertisement, availability of the product, etc. are the critical factors while taking buying decisions. All these determinants are uncontrollable and beyond the hand of consumers. To what extent farmers account them in making decisions for purchase of fertilizer is not known.

Price: Fertilizer price is not uniform. It includes cost of production, promotional expenses and taxes. Low price acts as motivator to buy while high price inhibits purchase; but low price casts doubt on product attributes. Product price also affects repeatpurchase behaviour (Chen, Liang, and Xie, 2016). Consumers with more experience in the marketplace generally have more accurate beliefs about the price distribution, which is consistent with learning (Matsumoto and Spence, 2016).

Quality: Product quality is important for surveillance of consumers (Tran, Brewster, Chidambaram, and Hurdle, 2015). The quality is set of attributes as judged by the customer to purchase products. Purchase intention is determined by quality (Yogi, 2015).

Brand: It is a name, term, sign, symbol or design or a combination of them, intended to identify the goods or services of one seller or group of sellers and to differentiate them from those of competitors. Many marketing communities have made significant investments in building brand (Habibi, Laroche, and Richard, 2016) as brand is the guiding force of customers' purchase intention. By identification with brand customer develops brand loyalty.

Advertisement: Advertisement is a very powerful tool in marketing. It is used for communicating business information to the present and prospective customers. It provides information about the features of the products, qualities, place of availability, different schemes offered, benefits of product, etc. It is important for both sellers and buyers. Buyers can compare products with similar products in the market.

In the backdrop of above description, this study aims at identifying the significance of the determinants to be considered by the farmers in making decision to purchase fertilizer.

\section{METHOD}

\section{The area}

Birbhum is an important district in the Rarh region of West Bengal state of India having a considerable area under undulating topography in the western part of the district. Many rivers and rivulets irrigate the district. The river, Ajoy divides this district from Burdwan. The predominant soil types are old alluvial and red lateritic with low to 
medium in organic carbon and phosphate content and medium to high in potash. The soil is acidic in nature. SuriSadar subdivision is a subdivision of the Birbhum district. It includes seven blocks. Out of them, Blocks -1 and 2 are populated with farmers. Data were collected from these two blocks.

\section{Participants}

Proportionate stratified random sampling was made to collect data from three categories of farmers - Small (land size 1-10 bighas ), Medium (land size 11-20 bighas), and big (land size more than 20 bighas). Land size includes only the cultivable land. The small $(n=146)$, medium $(n=43)$ and big $(n=11)$ farmers (total $=200)$ participated in this study. Socio-economic condition of farmers is poor. Table 1 shows that most of the farmers possessed own cultivable land (86\%). Their yearly income was less than Rs 40 thousand in Indian currency $(80 \%)$. They possessed kuttcha house $(65 \%)$ having two rooms $(75 \%)$. They had no separate kitchen $(82 \%)$, toilet $(67 \%)$, personal tractor $(92 \%)$, and personal vehicle $(68 \%)$.

Table 1 : Socio-economic status of the farmers ( $\mathrm{n} 200$ )

\begin{tabular}{lccc}
\hline Variables & Categories & Frequency & $\%$ out of 200 \\
Yearly income & Less than 20k & 65 & $33 \%$ \\
& $20 \mathrm{k}-40 \mathrm{k}$ & 93 & 47 \\
& $41 \mathrm{k}-60 \mathrm{k}$ & 35 & 18 \\
House condition & Above 60k & 7 & 4 \\
& Kuttcha & 130 & 65 \\
No. of rooms & Pukka & 70 & 35 \\
& 2 rooms & 150 & 75 \\
Separate kitchen & More than 2 rooms & 50 & 25 \\
Presence of toilet & Yes & 26 & 13 \\
Personal tractor & No & 164 & 82 \\
Personal vehicle & Yes & 66 & 33 \\
& No & 134 & 67 \\
Cultivable land (own) & Yes & 17 & 9 \\
& No & 183 & 92 \\
\hline
\end{tabular}

\section{Instruments}

A questionnaire was administered to collect data from the farmers. It consisted of two parts. Personal information section: It includes queries about name, age, years of farming experience, yearly income, house condition, number of rooms, separate kitchen, presence of toilet, personal tractor, personal vehicle, own presence of cultivable land. 
Fertilizer purchase decision questions: Five-point Likert type questions with 29 items were constructed after observing purchase behavior and focused group discussion with agricultural farmers. The questions related to the importance of price, landscape, crop types, brand, fertilizer quality, advertisement and soil quality on purchase decision of fertilizer. Farmers were asked to rate the items with five point response categories that ranged from most important to least important in purchase decision. High score indicates high importance.

\section{RESULTS AND DISCUSSION}

Success of agriculture marketing depends on satisfaction of farmers needs. Fertilizer has large share on agricultural marketing. This study tends to explore the significance of factors determining decisions to purchase fertilizers. Table 2 shows specific domain and item wise descriptive statistics. Generally, it is assumed that purchase decision of farmers depends significantly on price as socio-economic status is low. In this study, farmers of lower economic strata participated but they reported least interest in price (Mean=2.00, $\mathrm{SD}=1.20$ ). They are also not interested in bargaining (Mean=1.22, $S D=0.55)$ and even the budget $(M e a n=1.23, S D=0.56)$.

Table 2 : Mean and standard deviation of the significance of determinants of purchase decision of fertilizer

\begin{tabular}{|c|c|c|c|c|}
\hline $\begin{array}{c}\text { Determinants } \\
(1) \\
\end{array}$ & $\begin{array}{c}\text { S.L. No. } \\
(2)\end{array}$ & $\begin{array}{c}\text { Item } \\
(3) \\
\end{array}$ & $\begin{array}{c}\text { Mean } \\
(4) \\
\end{array}$ & $\begin{array}{l}\text { SD } \\
(5) \\
\end{array}$ \\
\hline \multirow[t]{6}{*}{ Price } & 1 & Before purchasing fertilizer I consider price & 1.51 & 0.93 \\
\hline & 2 & Bargain over the price & 1.22 & 0.55 \\
\hline & 3 & Collect information from other shops about price & 2.23 & 0.85 \\
\hline & 4 & Before purchasing fertilizer I always do budget with myself & 1.23 & 0.56 \\
\hline & 5 & If quality is good then I do not bargain over price & 3.80 & 0.56 \\
\hline & & Total & 2.00 & 1.20 \\
\hline \multirow[t]{4}{*}{ Landscape } & 1 & Purchase fertilizer after considering the fertility of the soil. & 3.41 & 0.88 \\
\hline & 2 & I do purchase the most saleable fertilizer of the area. & 3.39 & 0.87 \\
\hline & 3 & I prefer to buy fertilizer from the nearest shop & 2.68 & 1.06 \\
\hline & & Total & 3.16 & 1.00 \\
\hline \multirow[t]{4}{*}{ Types of crop } & 1 & I do purchase fertilizer depending on the type of crops. & 3.73 & 0.61 \\
\hline & 2 & $\begin{array}{l}\text { Quantity of purchasing fertilizer depends on the nature of } \\
\text { crop. }\end{array}$ & 3.79 & 0.56 \\
\hline & 3 & $\begin{array}{l}\text { I follow the co-farmers, whatever they purchase for the } \\
\text { particular type of crop. }\end{array}$ & 2.63 & 1.26 \\
\hline & & Total & 3.38 & 1.02 \\
\hline
\end{tabular}


10 I PYC Nepal Journal of Management, August 2016, Vol. IX, No. 1

\begin{tabular}{|c|c|c|c|c|}
\hline (1) & $(2)$ & (3) & (4) & (5) \\
\hline \multirow[t]{7}{*}{ Brand } & 1 & Before purchasing fertilizer I look after the brand. & 3.54 & 0.74 \\
\hline & 2 & $\begin{array}{l}\text { I collect information about different brands before } \\
\text { purchasing fertilizer. }\end{array}$ & 2.19 & 1.17 \\
\hline & 3 & I follow the co-farmers in preferring particular brand. & 2.90 & 1.03 \\
\hline & 4 & I do purchase the fertilizer of a particular brand. & 2.91 & 0.87 \\
\hline & 5 & $\begin{array}{l}\text { I do consider the recent market trend in preferring particular } \\
\text { brand. }\end{array}$ & 2.47 & 1.02 \\
\hline & 6 & $\begin{array}{l}\text { If ingredients of fertilizer are up to the mark then I do not } \\
\text { think about brand. }\end{array}$ & 2.80 & 1.02 \\
\hline & & Total & 2.80 & 1.07 \\
\hline \multirow[t]{5}{*}{ Quality } & 1 & $\begin{array}{l}\text { I do purchase fertilizer considering the subject of maximum } \\
\text { production within a short time. }\end{array}$ & 3.87 & 0.35 \\
\hline & 2 & $\begin{array}{l}\text { I do purchase fertilizer after considering the duration of } \\
\text { effectiveness }\end{array}$ & 3.25 & 0.77 \\
\hline & 3 & I do consider about the side effects of the fertilizers & 2.56 & 1.27 \\
\hline & 4 & $\begin{array}{l}\text { Prefer to purchase fertilizer considering both profit and } \\
\text { quality }\end{array}$ & 3.48 & 0.94 \\
\hline & & Total & 3.29 & 1.01 \\
\hline \multirow[t]{5}{*}{ Advertisement } & 1 & $\begin{array}{l}\text { Advertisement elicits the interest to purchase particular } \\
\text { fertilizer. }\end{array}$ & 2.74 & 1.06 \\
\hline & 2 & $\begin{array}{l}\text { Prefer to purchase fertilizer whose advertisement is exhibit } \\
\text { everywhere or maximum time. }\end{array}$ & 3.10 & 1.03 \\
\hline & 3 & $\begin{array}{l}\text { Purchase fertilizer after compairing the reality with the } \\
\text { advertisement. }\end{array}$ & 2.63 & 1.21 \\
\hline & 4 & Ad helps to be updated with recent trends. & 3.27 & 0.92 \\
\hline & & Total & 2.94 & 1.07 \\
\hline \multirow[t]{5}{*}{ Soil quality } & 1 & $\begin{array}{l}\text { I take decision to purchase particular fertilizer after follow the } \\
\text { agricultural programmes of tv/radio. }\end{array}$ & 2.46 & 1.06 \\
\hline & 2 & $\begin{array}{l}\text { I purchase fertilizer depending on the information of the local } \\
\text { agricultural dept. }\end{array}$ & 2.09 & 1.03 \\
\hline & 3 & $\begin{array}{l}\text { Practical experiences of the co-farmers helps me to } \\
\text { purchase particular fertilizer. }\end{array}$ & 3.37 & 0.83 \\
\hline & 4 & $\begin{array}{l}\text { Regular contact with the retailers helps to get information } \\
\text { about good fertilizer }\end{array}$ & 3.23 & 0.83 \\
\hline & & Total & 2.79 & 1.08 \\
\hline
\end{tabular}

Fertilizer market is huge and many companies present unique images and facilities through branding. Branding aims to establish a significant and differentiated presence in the market that attracts and retains loyal customers. But the study finds brand has little influence on farmers. Farmers are dithering about brand (Mean=2.80, $S D=1.07$ ). This uncertainty may be due to discrepancy between brand image and actual quality of fertilizers. Possibly, due to this reason, farmers reported not thinking of brand if fertilizer ingredients are up to the mark (Mean=2.80, $\mathrm{SD}=1.02$ ). 
Advertising success depends on perception constancy. This is revealed in the reporting of farmers. They prefer purchasing fertilizer whose advertisement is exhibited everywhere or for longer time (Mean=3.10, $S D=1.03$ ). But, farmers are dithering about advertisement for fertilizer purchase (Mean=2.94, SD=1.07). This dithering may be due to discrepancy between actual content and claimed contents of the advertisement (Khor and Zeller, 2014)

Use of fertilizer depends on quality of soil. Farmers know it very well but they are dithering to consider soil quality (Mean=2.79, $S D=1.08$ ) in fertilizer purchase. This is a serious issue. It suggests two things - ignorance about the use of fertilizer - soil quality linkage and random use of fertilizer. Random use may affect their crops. Lamb (2011) observed random use of fertilizer by the Indian farmers.

Farmers gave maximum importance on quality of crops in purchasing fertilizers. In this study, farmers are mainly paddy producers. They produce crop for family and for generating cash. There are several attributes of paddy on which farmers pay attention to purchase fertilizers. These attributes are: wholesomeness, appearance, colour, presence of foreign matter (organic and inorganic), damaged grains, broken grains, immature/ shriveled grains, weeviled grains, admixture and moisture content. Farmers know linkage of fertilizer and crop quality. The quantity of fertilizer is important as excessive or least amount may retard plant growth. Results show that farmers pay attention to nature (Mean 3.79 , SD 0.56 ), and types (Mean 3.73, SD 0.61) of crops in determining decision about the amount to purchase. As they experience difficulty to understand specific fertilizer and crop quality, they follow fellow farmers (Mean 2.63, SD 1.26).

Landscape plays role in fertilizer purchase (Mean 3.16, SD 1.00). They like to buy fertilizer that is most saleable (Mean 3.39, SD 0.87 ) rather than available at the local shop (Mean 2.68, SD 1.06).

\section{CONCLUSION}

To sum up, Indian farmers are very cautious in fertilizer purchase. They prefer soil quality, crop and fertilizer quality rather than price, brand and advertisement. Fertilizer purchase decision of farmers can be explained by the theory of planned behaviour.

The theory of planned behaviour evolved as the theory of reasoned action in 1980 s to predict an individual's intention to engage in a behaviour at a specific time and place (Ajzen, 1991). The theory was intended to explain all behaviours over which people have the ability to exert self-control. The key component to this model is behavioural intent. It assumes that behavioural intentions are influenced by the attitude about the likelihood that the behaviour will have the expected outcome and the subjective evaluation of the risks and benefits of that outcome. Results show that despite influences of price, brand and the advertisement, farmers intended to buy the fertilizer which is mostly used by the fellow farmers (social norm), their own and local people attitudes to the specific fertilizer. It suggests some training programmes for marketing the fertilizers by both the Government and private companies. 
Through extension training programmes, the Government can educate the farmers, the sharecroppers and the stockiest about soil quality examination and the linkage among fertilizer, crop, soil and seed qualities. As the Government has limited resources, training may be organized through private-public partnership. And the training should focus on soil testing, linkage between fertilizer and soil quality, specific warnings for uses of fertilizer, seed and crop quality examination, linkage between fertilizer and crop quality, awareness of specific sources for fertilizer purchase, etc.

Finally, the study concludes that purchase decision is not forced rather it is based on strong reasoning. As it is reason based, there is ample scope for designing the training program to increase sales of agricultural inputs and to protect the farmers from miscreants.

\section{REFERENCES}

Ajzen, I. (1991). The theory of planned behavior. Organizational Behavior and Human Decision Processes, 50, 179-211.

Chen, Z., Liang, X., \& Xie, L (2016). Inter-temporal price discrimination and satiety-driven repeat purchases. European Journal of Operational Research, 251(1), 225-236.

Habibi, M. R., Laroche, M., \& Richard, M. (2016). Testing an extended model of consumer behavior in the context of social media-based brand communities. Computers in Human Behavior, 62, 292-302.

Khor, L.Y., \& Z, M. (2014). Inaccurate fertilizer content and its effect on the estimation of production functions. China Economic Review, 30, 123-132.

Kottala, S. Y. (2015). An empirical and fuzzy logic approach to product quality and purchase intention of customers in two wheelers, Pacific Science Review B: Humanities and Social Sciences, 1(1), 57-69.

Lamb, R. (2011). Fertilizer use, risk, and off-farm labor markets in the semi-arid tropics of India. Department of Agricultural and Resource Economics Report, 23. Retrived from: http://ageconsearch.umn.edu/bitstream/57542/2/er23.pdf. dated 10.4.16.

Le-Thuy T. T., Philip J. B., Valliammai C., \& John F. H. (2015). Towards measuring the food quality of grocery purchases: an estimation model of the healthy eating index-2010 using only food item counts, Procedia Food Science, 4, 148-159.

Matsumoto \& Spence (2016). Price beliefs and experience: Do consumers' beliefs converge to empirical distributions with repeated purchases? Journal of Economic Behavior \& Organization, 126, 243-254.

Pokhrel, D. M., \& Thapa, G. B. (2007). Are marketing intermediaries exploiting mountain farmers in Nepal? A study based on market price, marketing margin and income distribution analyses. Agricultural Systems, 94(2), 151-164. 